\title{
Da constitucionalidade da taxa de vistoria de segurança contra incêndio ${ }^{1}$
}

Carlos Alexandre Amarantes ${ }^{2}$

Edgar Mitsuaki Fukuda ${ }^{3}$

\section{Resumo}

\begin{abstract}
O art. 145 §2 da Constituição Federal impôs uma limitação no critério quantitativo das taxas, determinando que estas jamais poderiam ter base de cálculo própria de impostos. Neste sentido, questiona-se a constitucionalidade da taxa municipal de segurança contra incêndio, que embora seja uma taxa de exercício de poder de polícia, possui base de cálculo própria do IPTU. Também outros critérios serão analisados em observância à Constituição Federal.
\end{abstract}

Palavras-Chave: Taxa de incêndio; Constitucionalidade.

\section{Introdução}

O legislador constituinte dispôs na Constituição Federal, mais precisamente, no capítulo atinente ao sistema tributário nacional (Título VI, Capítulo I, Seção I) os tipos de tributos passíveis de serem exigidos pelos entes federados.

Em seu art. 145, a Constituição Federal trata sobre os impostos, taxas e contribuições de melhoria.

Sobre as taxas ressalta a Carta Magna, no inciso II do mesmo artigo, a existência de duas espécies adotadas no sistema jurídico tributário brasileiro: as taxas pela utilização efetiva ou potencial de serviços públicos, específicos e divisíveis prestados ao contribuinte ou postos a sua disposição, denominada taxa de serviços públicos; e as taxas em razão do exercício do poder de polícia.

Determinou também a Constituição no §2을 do mesmo artigo que as taxas não podem ter base de cálculo própria de impostos.

A problemática em torno desta disposição é crescente, haja vista a dificuldade dos legisladores infraconstitucionais em determinar uma base de cálculo para as taxas, que seja diferente das utilizadas na cobrança dos impostos.

1 Trabalho apresentado na disciplina de Direito Tributário do Curso de Graduação de Direito da Universidade Estadual de Londrina.

2 Bacharelando do curso de Direito pela Universidade Estadual de Londrina. carlosdireitouel@hotmail.com

3 Bacharelando do curso de Direito pela Universidade Estadual de Londrina. edgarfukuda@hotmail.com 
A taxa é um tributo de difícil valoração quantitativa, de modo que seu maior problema esta no critério quantitativo. Também no critério temporal e material pela dificuldade de se estabelecer o que é poder de polícia e o momento em que ele ocorre.

A taxa de vistoria de segurança contra incêndio é apenas mais uma taxa municipal, considerada de exercício de poder de polícia, que possui algumas inconstitucionalidades a ser tratadas no presente estudo.

\title{
2 Norma de incidencia fiscal
}

\subsection{Hipótese tributária}

Os critérios da hipótese são: Material, Espacial e Temporal.

A hipótese, como proposição descritiva de situação objetiva real, no ensinamento de Lourival Vilanova (1997, p. 46)

\begin{abstract}
É construída pela vontade do legislador que recolhe os dados do evento fático que deseja disciplinar, qualificando-os de forma normativa com fatos jurídicos. Mas este descritor, que é o antecedente ou suposto da norma, está introduzido na linguagem descritiva do direito positivo, porque, mesmo formulado por um conceito de teor descritivo, vem atrelado à conseqüência da regra, onde reside a estipulação da conduta (prescritor), meta finalística e razão da própria existência do direito. Por isso, os conceitos jurídicos veiculados na hipótese não estão sujeitos aos valores de verdade ou falsidade, como também as proposições descritivas que os cientistas emitem. As hipóteses das normas jurídicas valem ou não valem, como também as respectivas conseqüências (prescritores) têm validade ou invalidade.
\end{abstract}

Busca-se a partir de agora estudar a norma de incidência fiscal da taxa de vistoria de segurança contra incêndios, cobrada pelo município de Londrina.

Lembrando-se que se trata de uma taxa de poder de polícia, haja vista a necessidade de fiscalização exigida pelo Poder Público em face da segurança de seus contribuintes.

Dispõe o art. 78 do Código Tributário Nacional:

Art. 78. Considera-se poder de polícia a atividade da administração pública que, limitando ou disciplinando direito, interesse ou liberdade, regula a prática de ato ou abstenção de fato, em razão de interesse público concernente à segurança, à higiene, à ordem, aos costumes, à disciplina da produção e do mercado, ao exercício de atividades econômicas dependentes de concessão ou autorização do Poder Público, à tranqüilidade pública ou ao respeito à propriedade e aos direitos individuais ou coletivos. 
Neste sentido, busca-se estudar a norma de incidência fiscal da presente taxa municipal, em consonância com o disposto no Código Tributário Nacional e Constituição Federal.

\subsection{Critério material}

Dispõe o Código Tributário Municipal de Londrina, em seu arts. 204 e 205:

Art. 204 A taxa de vistoria de segurança contra incêndio incidirá sobre estabelecimentos comerciais, industriais, prestadores de serviços e edifícios com 3 (três) ou mais pavimentos ou construções com metragem superior a $750 \mathrm{~m} 2$ ( setecentos e cinqüenta metros quadrados ), localizados no Município.

Analisando a presente norma, infere-se que o critério material da "taxa de prevenção de incêndios" é justamente a realização de vistoria, que deve ser exercida em estabelecimentos comerciais, industriais, prestadores de serviços e edifícios residenciais com mais de 03 andares ou construções com metragem superior a $750 \mathrm{~m}^{2}$.

Portanto, somente estes imóveis serão fiscalizados como forma de prevenção de incêndios.

O critério material parece deveras justo, afinal nestes estabelecimentos a ocorrência de um incêndio poderia ser trágico, não só nos estabelecimentos comerciais e industriais, onde a existência de muitos trabalhadores e objetos poderia proporciona-lo, mas também nos edifícios residenciais, onde devido ao número de pessoas domiciliadas, e a altura do edifício, poderia configurar resultado mais danoso.

Por isso, nestes estabelecimentos costuma ocorrer mais incêndios, além disso, quando neles ocorre, resulta num trabalho mais árduo e difícil aos bombeiros, que deverão ser extremamente cautelosos no socorro de bens e de pessoas.

\subsection{Critério espacial}

O final do art. 204 define o critério espacial da hipótese, ao dispor que a taxa será aplicável aos imóveis descritos: estabelecimentos comerciais, industriais, prédios com mais de três andares e construções com mais de $750 \mathrm{~m}^{2}$ que estejam localizados dentro do município. 
Portanto, esta taxa só pode ser cobrada nestes estabelecimentos que estejam localizados no Município de Londrina.

\subsection{Critério temporal}

O art. 205 define o momento de incidência da taxa, ou seja, o momento em que deve ocorrer o critério material da hipótese.

Art. 205. A taxa de vistoria de segurança contra incêndio tem como fato gerador o controle permanente, efetivo ou potencial, exercido anualmente pelo Corpo de Bombeiros da Polícia Militar do Estado do Paraná, decorrente do poder de polícia do Município, bem como a expedição de visto de conclusão ('habite-se') em construções novas, reformadas ou ampliadas, relativamente aos imóveis citados no artigo 204.(Nova redação dada pela Lei 8.671/01).

O Corpo de Bombeiros da Polícia Militar do Estado do Paraná deverá cobrar a taxa de vistoria de segurança contra incêndio logo após realizar o controle anual nos referidos imóveis descritos no art. 204, ou ainda, quando tiver que expedir "habite-se" para a construção, reforma ou ampliação destes.

Vê-se que o Corpo de Bombeiros é responsável pela observação destes estabelecimentos, de modo que deverá também aprovar a construção, reforma ou ampliação dos mesmos. Por isso, é chamada de taxa de vistoria e não apenas de taxa de incêndio. A finalidade da mesma é a vistoria como uma prevenção contra o incêndio.

Pelo vocábulo taxa de incêndio poderia se supor que fosse uma taxa pagável ao Corpo de Bombeiros apenas pelo trabalho destes realizado no caso de um incêndio.

Há grande discussão que poderia ser travada no critério temporal da hipótese, no tocante à disponibilidade do órgão público como pressuposto de cobrança de taxa.

Isto é motivo de discussão em várias taxas de poder de polícia e também o é no caso desta também, pois o Corpo de Bombeiros não realiza vistoria todo ano nos estabelecimentos, porém todo ano os contribuintes devem pagar o tributo para a mantença deste órgão, sobre o velado fundamento de que estariam fiscalizando todos os anos os mesmos estabelecimentos. 


\subsection{Relação jurídica tributária}

No estudo da norma de incidência fiscal, importante não só estabelecer a hipótese tributária, que é composta pelos critérios material, espacial e temporal, mas também observar a relação jurídica que se instaura a partir da hipótese.

\subsubsection{Critério pessoal}

Segundo Carvalho (1999, p. 212-214), o critério pessoal apresenta a delimitação dos sujeitos da relação jurídica tributária. De um lado, o sujeito ativo, que é o titular do direito subjetivo de exigir a prestação pecuniária. De outro, o sujeito passivo, que é a pessoa física ou jurídica, privada ou pública, de quem se exige o cumprimento da prestação pecuniária, nos nexos obrigacionais; e insuscetível de avaliação patrimonial nas obrigações que veiculam meros deveres instrumentais ou formais.

\subsubsection{Sujeito passivo}

A partir do momento em que o Corpo de Bombeiros Militar do Estado do Paraná faz a vistoria anual nos estabelecimentos, do município de Londrina, mencionados no art. 204, ou então concede "habite-se" para construção, reforma ou ampliação destes, ocorre a hipótese tributária da taxa de vistoria de segurança contra incêndio, onde sujeito passivo é aquele que recebeu o atendimento dos bombeiros.

Ou seja, sujeito passivo, é qualquer pessoa que seja responsável pelos imóveis descritos no art. 204, ou seja, o beneficiário do ato, que deverá pagar aos bombeiros pela fiscalização ou vistoria havida, ou ainda pela concessão de "habite-se".

\subsubsection{Sujeito ativo}

"Sujeito ativo da obrigação é a pessoa jurídica de direito público titular da competência para exigir o seu cumprimento" (art. 119/CTN).

Sujeito ativo nesta relação jurídica tributária é o Corpo de Bombeiros Militar do Estado do Paraná que, como ente do Poder Público, deverá realizar, em prol do contribuinte, a vistoria de segurança, objeto da presente norma jurídica tributária municipal. 
Existe um outro problema em questão no pagamento desta taxa que é com respeito à incompetência do município em arrecadar este tributo, haja vista que o Corpo de Bombeiros é órgão estadual e, portanto, esta taxa deveria ser paga ao Estado, não ao município, mas esta questão será tratada no tópico a seguir sobre lançamento.

\subsection{Critério quantitativo}

Sem dúvida um dos maiores problemas das taxas é definir seu critério quantitativo, ou seja, sua base de cálculo e alíquota.

Como foi dito inicialmente, os legisladores competentes para a criação das taxas tem dificuldade para definir uma base de cálculo que seja proporcional ao custo das despesas efetivadas pelo ente público para atender o contribuinte. Deste modo, acabam por criar taxas com base de cálculo semelhantes a dos impostos, culminando numa inconstitucionalidade.

\subsubsection{Base de cálculo e alíquota}

O Código Tributário Municipal não especifica qual é a base de cálculo adotada no caso da taxa de vistoria de segurança contra incêndios.

Porém, há um anexo na referida lei que traz as alíquotas aplicáveis a esta taxa, em que se considera não só o risco que o estabelecimento possa trazer à sociedade pela possibilidade da ocorrência de incêndio, mas também leva em consideração o tamanho da construção do estabelecimento, conforme tabela abaixo:

\section{Tabela 1}

\begin{tabular}{c|l|c|}
$\begin{array}{c}\text { GRUPO } \\
\text { DE } \\
\text { RISCO }\end{array}$ & \multicolumn{1}{|c|}{ ATIVIDADE } & $\begin{array}{c}\text { Valor em } \\
\text { Real por } \\
\text { ano }\end{array}$ \\
\hline \hline A & $\begin{array}{l}\text { Induistria ou comércio de tintas, vernizes, gasolina, álcool, benzina, } \\
\text { graxa. Óleo e oleaginosas, querosene, celulose, breu, fogos de } \\
\text { artifício armas e. municños exnlosivos nostos de oasolina e }\end{array}$ & \\
\hline
\end{tabular}




\begin{tabular}{|c|c|c|}
\hline & lubrificação de veículos, depósitos de gás liquiefeito de petróleo. & 40,00 \\
\hline$B$ & $\begin{array}{l}\text { Induistria ou comércio de móveis; laminados; serrarias; artefatos de } \\
\text { madeira; móveis estofados e de vime e derivados; comércio ou } \\
\text { induistria de tecidos, roupas, cortinas, tapetes, estofados, algodão, } \\
\text { estopa, armarinhos, crinas, oleados, colchoarias, borrachas, } \\
\text { plásticos, couros, peles, calçados. }\end{array}$ & 38,00 \\
\hline$C$ & $\begin{array}{l}\text { Casas de diversões; cinemas; teatros e congêneres; estabelecimentos } \\
\text { de hotelaria, pensões, dormitórios e similares; hospitais; clinicas e } \\
\text { casas de saúde. }\end{array}$ & 36,00 \\
\hline$D$ & $\begin{array}{l}\text { Indústria ou comércio de produtos químicos e farmacêuticos; usinas } \\
\text { siderúrgicas e metalúrgicas; indústria e comércio de automóveis e } \\
\text { autopeças; oficinas mecânicas em geral e silos em geral. }\end{array}$ & 34,00 \\
\hline$E$ & $\begin{array}{l}\text { Papelarias, livrarias, tipografias, gráficas e depósitos de papéis, } \\
\text { jornais ou revistas. }\end{array}$ & 32,00 \\
\hline$F$ & $\begin{array}{l}\text { Indústria, comércio e depósitos de material de construção; comércio } \\
\text { de cereais; bares; material de limpeza doméstica; armazéns gerais; } \\
\text { secos e molhados e produtos alimentícios. }\end{array}$ & 30,00 \\
\hline \multirow[t]{2}{*}{$G$} & Indústria, comércio ou depósito de material de construção, comércio & \\
\hline & $\begin{array}{l}\text { de gás liqüefeito de petróleo (GLP), empresas de transporte com } \\
\text { depósito, ornamentação, ferragens, metais, material elétrico e } \\
\text { sanitário, joalherias, aparelhos eletrodomésticos, óticas, esportes, } \\
\text { recreação, caça-e-pesca, brinquedos, bijuterias. }\end{array}$ & 28,00 \\
\hline$H$ & $\begin{array}{l}\text { Moinhos; torrefação; descascadores; indústrias de massas e } \\
\text { biscoitos; padarias, confeitarias e congeneres; casas de frios; } \\
\text { lanchonetes; restaurantes; sorveterias e similares. }\end{array}$ & 26,00 \\
\hline$I$ & $\begin{array}{l}\text { Induistria, comércio de carnes e peixes, matadouros, abatedores, } \\
\text { laticínios e conservas. }\end{array}$ & 24,00 \\
\hline$J$ & $\begin{array}{l}\text { Indústria e comércio de máquinas e aparelhos agricolas, cirúrgicos, } \\
\text { dentários, hospitalares, domésticos e de escritórios; indústria e } \\
\text { comércio de produtos de uso agropecuário. }\end{array}$ & 22,00 \\
\hline$L$ & $\begin{array}{l}\text { Agências lotéricas e similares, lavanderia e tinturaria, malharias, } \\
\text { ateliê de costura, alfaiataria, salões de beleza e barbearias. }\end{array}$ & 20,00 \\
\hline$M$ & $\begin{array}{l}\text { Indústria e comércio de cerâmicas, ladrilhos e similares; oficinas de } \\
\text { consertos em geral não-mecânicos. }\end{array}$ & 17,00 \\
\hline$N$ & $\begin{array}{l}\text { Comércio de doces e derivados, bonbonnières, frutas, hortaliças, } \\
\text { floriculturas, produtos agricolas e hortigranjeiros, escritórios } \\
\text { profissionais e consultórios, bancas ou revenda de jornais e revistas, } \\
\text { empresas de transporte sem depósito. }\end{array}$ & 15,00 \\
\hline
\end{tabular}




\section{NORMAS DE APLICAÇÃO:}

I- Os estabelecimentos comerciais e industriais não previstos nos grupos acima serão neles classificados pelo Corpo de Bombeiros, por similitude.

2 - Quando o estabelecimento tiver múltipla atividade, será enquadrado pelo maior risco.

3 - As edificações com destinação de uso especificado no Grupo " O terão a taxa elevada em cem por cento, quando a sua área total for ocupada por mais de 25 locações.

4 - Em qualquer caso, o valor mínimo a ser cobrado será de $\mathrm{R} \$ 20,00$ (vinte reais)

\section{Tabela 2}

\begin{tabular}{|l|c|}
\hline \multicolumn{1}{|c|}{ AREA CONSTRUIDA } & \% SOBRE O RISCO \\
\hline \hline Até $60 \mathrm{~m}^{2}$ & $60 \%$ \\
\hline $61 \mathrm{~m}^{2}$ a $100 \mathrm{~m}^{2}$ & $80 \%$ \\
\hline $101 \mathrm{~m}^{2}$ a $200 \mathrm{~m}^{2}$ & $100 \%$ \\
\hline $201 \mathrm{~m}^{2}$ a $400 \mathrm{~m}^{2}$ & $120 \%$ \\
\hline $401 \mathrm{~m}^{2}$ a $600 \mathrm{~m}^{2}$ & $140 \%$ \\
\hline $601 \mathrm{~m}^{2}$ a $1.000 \mathrm{~m}^{2}$ & $160 \%$ \\
\hline $1.001 \mathrm{~m}^{2}$ a $2.000 \mathrm{~m}^{2}$ & $180 \%$ \\
\hline $2.001 \mathrm{~m}^{2}$ a $4.000 \mathrm{~m}^{2}$ & $200 \%$ \\
\hline $4.001 \mathrm{~m}^{2}$ a $6.000 \mathrm{~m}^{2}$ & $250 \%$ \\
\hline ACIMA DE $6.001 \mathrm{~m}^{2}$ & $300 \%$ \\
\hline
\end{tabular}

Veja que se a taxa é cobrada em função da área do imóvel - o que é o caso, já que quanto maior o imóvel, maior será o valor da taxa - ela se torna inconstitucional, por se utilizar de fator determinante da base de cálculo do IPTU. 
De acordo com a tabela 02 se a propriedade tiver até $60 \mathrm{~m}^{2}$, o contribuinte paga alíquota de $60 \%$ sobre o valor de risco apresentado na tabela 01 , chegando até a alíquota de $300 \%$, no caso da propriedade ter mais de $6.001 \mathrm{~m}^{2}$.

Partindo dessa premissa, a taxa de vistoria de segurança contra incêndio seria inconstitucional, já que toma como base de cálculo não só o risco, mas também o tamanho da propriedade, o que reflete indiretamente no valor venal do imóvel, base de cálculo do Imposto sobre propriedade territorial urbana (IPTU).

Correto o posicionamento do advogado mineiro Marco Aurélio Bicalho de Abreu Chagas ao entender pela inconstitucionalidade das chamadas taxas de incêndio, pela utilização de uma base de cálculo que, indiretamente, é a mesma do IPTU, explica ele:

\footnotetext{
Embora, pode-se argumentar que a área do imóvel não seja o único elemento da base de cálculo da taxa em discussão, ela o integra, sendo determinante para a fixação do montante devido pelo contribuinte. $E$, ao repercutir no cálculo de imposto, sua utilização como aspecto quantitativo da taxa está vedada (CHAGAS, 2004).
}

Sendo assim, este tributo de caráter municipal, que, aliás, é cobrado em vários municípios, inclusive em Londrina, infringiria o art. $145, \S 2^{\circ}$, que determina que "as taxas não poderão ter base de cálculo própria de impostos".

\section{Lançamento}

O lançamento deve ocorrer no momento em que se expede uma norma concreta individual, demonstrando a ocorrência do evento tributário que, teve correspondência com a hipótese tributária e, portanto, incutiu na obrigação de pagar o tributo.

Como se sabe, o lançamento pode ser de oficio, quando realizado pelo Poder Público, ou por homologação, quando feito pelo próprio contribuinte.

No caso do tributo em questão, a taxa de vistoria de segurança contra incêndio, deverá ser paga, quando o Poder Público, representado no caso pelo Corpo de Bombeiros, lançará norma concreta individual para que o contribuinte pague anualmente o tributo. Portanto, trata-se de lançamento de oficio.

Dispõe o Código Tributário Municipal de Londrina: 
Art. 210. O lançamento será feito quando da abertura do estabelecimento ou expedição do visto de conclusão ('habite-se') e renovado anualmente, mediante lançamento de ofício.

Pela disposição legal, infere-se que lançamento é feito quando para concessão de "habite-se" e deve ser pago anualmente, como se fosse uma renovação ou fiscalização anual.

Entra-se aqui em dois embates. Primeiro, quanto à incompetência municipal para a cobrança de um tributo que deveria ser estatal, face à natureza estatal do órgão realizador do poder de polícia (Corpo de Bombeiros Militar do Estado do Paraná), o que denota ser uma taxa estatal, não municipal.

Segundo infringe-se o critério material e temporal da hipótese, porque o Corpo de Bombeiros não realiza efetivamente o exercício de poder de polícia, no entanto, cobra a taxa anualmente, como se todo ano o realizasse; o contribuinte paga pela disponibilidade do órgão e não pelos seus serviços efetivamente exercidos, o que já foi discutido no item 2.4, infringindo a retributividade, que é principio essencial da taxa.

\section{Deveres instrumentais}

A lei municipal de Londrina impõe como dever instrumental da taxa de vistoria de segurança contra incêndio, quando para renovação de alvará dos estabelecimentos previsto no art. 204, perante o Corpo de Bombeiros, deve-se apresentar o certificado ou laudo de vistoria de segurança contra incêndio, que foi concedido pelo Corpo de Bombeiros na expedição do "habite-se" de construção.

Art. 206 Não serão renovados alvarás de licença para localização nos imóveis descritos no artigo anterior que não apresentarem na repartição competente o certificado ou laudo de vistoria de segurança contra incêndio, emitido pelo Corpo de Bombeiros da Polícia Militar do Estado do Paraná.

O art. 207 também traz um dever instrumental, que condiciona retirada de alvará na Prefeitura, ao que denota para reforma ou ampliação de estabelecimento, apenas com a apresentação do certificado ou laudo de vistoria expedido pelo Corpo de Bombeiros. 
Art. 207 A expedição de alvarás de licença para localização e do visto de conclusão ('habite-se') pelo Município, fica condicionada à apresentação prévia do certificado ou laudo de vistoria, quando a atividade ou condições da edificação, relativamente ao grau de risco exigir, conforme for estabelecido em regulamento próprio, mediante o pagamento antecipado da respectiva taxa.

Destaca-se que, segundo a lei municipal, o não cumprimento das normas de segurança ditadas pelo Corpo de Bombeiros, enseja a aplicação de sanções administrativas, contidas no art. 211 do Código Tributário Municipal de Londrina. Trata-se da chamada norma sancionatória.

Art. 2110 não cumprimento das normas de segurança recomendadas pelo Corpo de Bombeiros, pela Legislação Municipal e outras normas de segurança de âmbito federal ou estadual, implicarão, isoladas ou cumulativamente, além das responsabilidades específicas cabíveis, nas seguintes sanções administrativas:

I - advertência;

II - multa de até 327,60 UFIR;

III - multa equivalente ao dobro da sanção anterior, a cada reincidência;

IV - suspensão, impedimento ou interdição temporária do estabelecimento, prédio ou locação;

V - denegação ou cancelamento do alvará de licença para localização e do visto de conclusão ('habite-se');

Parágrafo único - O contribuinte reincidente poderá ser submetido a sistema especial de fiscalização.

\section{Dos argumentos contra a natureza do tributo}

Muitos juristas do campo de direito tributário alegam que a taxa de vistoria de segurança contra incêndio, que em outros municípios é chamada de taxa de incêndio, não tem natureza de taxa, por não estar preenchidos os requisitos de especificidade e divisibilidade dos serviços prestados pelo Poder Público, no caso, pelo Corpo de Bombeiros.

Destaca Marco Aurélio Bicalho de Abreu Chagas (2004):

Essa cobrança é flagrantemente inconstitucional, porque o serviço de prevenção e extinção de incêndios, resgate e salvamento, é inespecífico, pois favorece não apenas os proprietários ou possuidores de bens imóveis, mas a coletividade em geral, mesmo porque o sinistro pode atingir também os bens móveis e ameaçar vidas humanas e de semoventes. E o resgate e salvamento favorecem todos aqueles que eventualmente se encontrem em situação de risco no município, mesmo que não sejam proprietários ou possuidores de imóveis e sequer morem na cidade. E, ademais, essas atividades são indivisíveis, pois não se pode medir o quanto cada munícipe, proprietário ou não, é beneficiado com sua existência, ou seja, se trata de serviço genérico e indivisível colocado à disposição de todos, indistintamente, sendo, pois, indevida a recomposição de seus custos através de 
taxa, de maneira que se afigura ilegal a cobrança do tributo nos moldes pretendidos pelo Estado.

O mesmo defendeu o procurador Robespierre Foureaux Alves, também em artigo publicado na internet:

Não foi outra a conclusão a que chegou o Eg. 1ํ Tribunal Alçada Cível de São Paulo:

TAXA - Incêndio. Municipalidade de Guarulhos. Exercício de 1999. Serviços de segurança destinado à toda coletividade. Não atendimento aos requisitos legais da especificidade e divisibilidade. Cobrança indevida. Recursos improvidos.

(10 TACSP, 11a C. Fér., AP 0947950-3 - (39603), Guarulhos, Rel. Juiz Antonio Marson - J. 08.02.2001.) Por fim, também nesse diapasão, já se manifestou recentemente o Tribunal de Justiça do Distrito Federal e Territórios, ao suspender, em sede de liminar proferida na Ação Direta de Inconstitucionalidade n.o 2001.00.2.005467-6, a eficácia da cobrança da "Taxa de Fiscalização, Prevenção e Extinção de Incêndio e Pânico", julgamento proferido em 18.09.2001. O que, pelo exposto, fica claro que o serviço de extinção de incêndios só pode ser classificado como "uti universi" ou geral, sendo prestado à comunidade como um todo, indistintamente, sendo por isso inconstitucional e ilegal a criação de taxa para a sua manutenção, ainda mais quando a cobrança alcança somente os proprietários de bens imóveis localizados na zona urbana de alguns municípios mineiros, como ocorre no caso em tela (ALVES, 2004).

Refuta-se os argumentos apresentados por estes juristas, já que quanto à natureza do tributo em questão não dúvida, trata-se de taxa de poder de polícia.

O serviço do Corpo de Bombeiros deveria ser o efetivo policiamento dos estabelecimentos - aqueles que ofereçam risco de incêndio - para que não venham afetar a tranqüilidade social, tal qual prescreve o art. 178 do CTN.

Não é se trata de um serviço uti universi, mas sim de um poder de policia exercido em face apenas dos estabelecimentos que causam risco de incêndio e que tenha como último efeito gerar um caos social.

\section{Conclusão}

Conclui-se, por todos os argumentos expostos, que a taxa de segurança contra incêndios, cobrada, inclusive, pelo Município de Londrina, seria inconstitucional. Primeiro porque atenta quanto ao critério temporal e material da hipótese ao instituir que o tributo deve ser cobrado pela disponibilidade do órgão de Corpo de Bombeiros em prestar serviços à sociedade, o que é incorreto, já que se trata de uma taxa de poder de polícia, que deveria 
ser cobrada no momento em que o Corpo de Bombeiros faz a devida vistoria no estabelecimento.

No tocante ao critério quantitativo também o tributo se mostra em confronto com disposição constitucional, ao instituir que esta taxa deverá ser quantificada por meio do tamanho do estabelecimento, refletindo no valor venal do imóvel, que é base de cálculo de um imposto, o IPTU.

Quanto ao lançamento também não é respeitado os mandames constitucionais, já quem deveria faze-lo, ainda que de ofício, seria o Estado do Paraná, não o município de Londrina, porque quem executa os serviços é o Corpo de Bombeiros do Estado do Paraná.

Deste modo, fica prejudicada a norma de incidência fiscal da hipótese tributária da taxa de vistoria de segurança contra o incêndio, conhecida em outros municípios, como taxa de incêndio.

\section{Referências}

ALVES, Robespierre Foureaux. Da Inconstitucionalidade da Cobrança da "Taxa de Incêndio". Jus navigandi, Teresina, v. 8, n. 338, 10 jun. 2004. Disponível em:

<http://jus2.uol.com.br/doutrina/texto.asp?id=5317>. Acesso em: 24 nov. 2006.

CARRAZZA, Roque Antonio. Curso de Direito Constitucional Tributario. 20. ed. São Paulo: Malheiros, 2004.

CARVALHO, Paulo de Barros. Curso De Direito Tributário. 12. ed. ver. amp. São Paulo: Saraiva, 1999.

CHAGAS, Marco Aurélio Bicalho de Abreu. Por Que Não Pagar a "Taxa" De Incêndio? Jus Navigandi, Teresina, v. 8, n. 310, 13 maio 2004. Disponível em:

<http://jus2.uol.com.br/doutrina/texto.asp?id=5245>. Acesso em: 25 nov. 2006.

VILANOVA, Lourival. As estruturas lógicas e o sistema do direito positivo. Revista Dos Tribunais, 1997. 
